\title{
Study on the Location of Distributed Distribution Centers: Considering Dual Marketing Channel in B2C E-commerce Environment
}

\author{
Debao Dai ${ }^{1, a,{ }^{*}}$ and Xiaohui Gu${ }^{1, b}$ \\ ${ }^{1}$ College of Management, Shanghai University, Shanghai, 200444, China \\ a daidebao@163.com, ${ }^{\mathrm{b}}$ 18817678752@163.com
}

Keywords: Distributed distribution centers; Location; Dual marketing channel; B2C

\begin{abstract}
The rapid development of Internet and e-commerce makes the "information flow" and "capital flow" in commercial activities so easy, however "physical flow" has been at a low level. This paper proposes solution of distributed distribution centers (DDCs) based on the dual marketing channel policy. Considering the two factors of supply chain cost and delivery service level, a biobjective optimization model based on mixed integer programming is established. The number and location of DDCs are determined by model to improve the distribution efficiency of B2C commerce. Finally the validity of the model is verified by a numerical experiment. The result shows that establishment of DDCs is more cost-effective than building a single distribution center while the level of delivery has been significantly improved.
\end{abstract}

\section{Introduction}

Over the past decade or so, the rapid development and growing maturity of Internet technology has made physical flow easier ever before. However, statistics shows that more than $70 \%$ of online complaints are related to logistics in e-commerce, especially the package damage and delivery delay. Consumer tolerance for delivery services is extremely low. How to improve delivery service level, especially the issue of time efficiency has become an urgent problem.

Comparison of two distribution models: traditional multi-echelon distribution model and online direct sales model. Although the order acquisition and payment is at a disadvantage, but the traditional multi-echelon distribution model is not useless; Logistics is more reasonable at least. In this model, the physical flow needs going through multiple distributors, in the form of "Warehouse to the warehouse" with a certain batch; This kind of physical flow occurs before the consumer buying behavior. In the second model, the goods are delivered directly from plant to consumers with the help of express service; Physical flow occurs after the consumer buying behavior ${ }^{[1]}$. Compare the two models: the former is "zero for the whole, bulk sale, warehouse to warehouse, space for time", while the latter is "whole is zero, single sale, warehouse to individual, time for space" $^{\prime[2]}$. So the delivery time of the former is far less than the latter.

Based on the background, the main research purpose of this paper has been determined: To explore how the distribution center (DC) should be located with the condition of dual marketing channel policy in the $\mathrm{B} 2 \mathrm{C}$ e-commerce environment. At home and abroad, research on the distribution center location (DCL) covers a wide range of content. In general, it can be divided into two categories: General DCL problems and constrained DCL problems ${ }^{[3]}$. According to the number of DCs, General DCL problems can be divided into: single DCL problems, dual DCL and multiple DCL problems. The problem of single DCL was first proposed by Alfred Webber in 1909 to minimize the total distance between warehouses and customers. The method used to solve this problem is the combination of gravity method and fuzzy analytic hierarchy process. Firstly, several candidate addresses are selected by gravity method, and then the candidate addresses are selected by fuzzy analytic hierarchy process (AHP) to get the best site selection scheme ${ }^{[4]}$.

Constrained DCL problems can generally be divided into five categories. When the distance between the two DCs is too large, it is necessary to limit the distance in order to reduce the cost and time ${ }^{[5]}$. The problem of capacity-constrained multiple DCL is generally used to control cost and risk ${ }^{[6]}$; It existences risk to store high-value products in large quantities. For this reason, it is essential to limit the capacity of the DC ${ }^{[7]}$. The problem of road capacity-constrained multiple DCL 
is generally used to figure out some actual questions: traffic problems and restrictions on the number of vehicles and so on. Time-constrained DCL issues take into account the time-response requirements for each distribution point. In the context of stochastic demand, Jiuping $\mathrm{Xu}$, Liming Yao and Xiaodan Zhao considered chance-constrained DCL issue, they developed a multi-objective programming model with stochastic fuzzy coefficients, and proposed a genetic algorithm based on spanning tree to solve this problem.

This paper proposed a distributed DC solution based on the dual marketing channel policy, taking into account the two aspects of supply chain cost and delivery service level.

A bi - objective optimization method is proposed based on mixed integer programming model; the quantity and location of DCs are determined by the model. Section 2 of this research describes the problem of distributed DCL in the context of dual marketing channel policy; Related assumptions, major costs and models are also introduced. Section 3 displays a numerical analysis to verify the validity of the model which is solved by Lingo software. Finally, the conclusion and limitations of this paper are expounded, and suggestions for future research are given in the section 4 .

\section{Problem Definition and Modeling}

Consider a brand retail. There are L suppliers, $\mathrm{m}$ DCs for its online retail stores (RSs) to provide storage and distribution services, $\mathrm{n}$ stores as the region's offline distribution channels and $\mathrm{n}$ consumer clusters (CCs). Consumers' online purchase channel can only be the local store. In other words, a consumer from city A can not shop in the city B. Figure 1 shows the logical relationship of the three-echelon supply chain which has dual marketing channels.

We made the following assumptions: (1)Only one product; (2)A city is a CC; (3) Each city has only one store as an offline distribution channel; (4) The capacity and number of DCs are bounded; (5)The maximum capacity of each DC is known; (6)The fixed rental costs, unit management costs, unit distribution costs of DCs are known; (7)The transportation prices from factory to DC are known; (8) The transportation prices from DC to CC are known; (9) The total production capacity of the plant is known, and the demand for each $\mathrm{CC}$ is known.

We considered the following major costs: (1) The transportation cost from factory to DC; (2)The transportation cost from DC to CC; (3)The unit management cost of DCs; (4) The fixed rental costs of DCs; (5)The unit management cost of RSs.

\section{Objective functions:}

$$
\begin{aligned}
& \text { OBJ1: } \min =\sum_{k=1}^{L} \sum_{i=1}^{m} w_{k i} v_{k i}+\sum_{i=1}^{m} \sum_{j=1}^{n} h_{i j} q_{i j}+\sum_{k=1}^{L} \sum_{i=1}^{m} g_{i} w_{k i}+\sum_{i=1}^{m} f_{i} z_{i}+\sum_{i=1}^{m} \sum_{u=1}^{n} r_{u} t_{i u} \\
& \text { OBJ2: } \min =\sum_{i=i}^{m} \sum_{j=1}^{n} y_{i j} z_{i}
\end{aligned}
$$

We explicitly consider two objective functions. OBJ 1 measures the total cost. The first part is the transportation cost from factory to DC, the second part is the transportation cost from DC to CC; the third part is the unit management cost of DCs; the fourth part is the fixed rental costs of DCs; And the last part is the unit management cost of RSs. OBJ 2 measures the total distance from DC to $\mathrm{CC}$; Without regard to traffic jams, the delivery time efficiency is measured by the distribution distance.

\section{Parameters:}

$\begin{array}{llll}\mathrm{P}_{\mathrm{k}} & \mathrm{Plants}, \mathrm{P}=\left\{\mathrm{P}_{1}, \mathrm{P}_{2}, \ldots, \mathrm{P}_{\mathrm{K}}, \ldots \mathrm{P}_{\mathrm{L}}\right\} & \mathrm{W}_{\mathrm{i}} & \mathrm{DC}, \mathrm{W}=\left\{\mathrm{W}_{1}, \mathrm{~W}_{2}, \ldots, \mathrm{W}_{\mathrm{i}}, \ldots \mathrm{W}_{\mathrm{m}}\right\} \\ \mathrm{C}_{\mathrm{j}} & \mathrm{CC}, \mathrm{C}=\left\{\mathrm{C}_{1}, \mathrm{C}_{2}, \ldots, \mathrm{C}_{\mathrm{j}}, \ldots, \mathrm{C}_{\mathrm{n}}\right\} & \mathrm{S}_{\mathrm{u}} & \mathrm{RS}, \mathrm{S}=\left\{\mathrm{S}_{1}, \mathrm{~S}_{2}, \ldots, \mathrm{S}_{\mathrm{u}}, \ldots, \mathrm{S}_{\mathrm{n}}\right\} \\ \mathrm{x}_{\mathrm{k}} & \text { The distance from } \mathrm{P}_{\mathrm{k}} \text { to } \mathrm{W}_{\mathrm{i}} & \mathrm{v}_{\mathrm{ki}} & \text { The unit transportation cost from } \mathrm{P}_{\mathrm{k}} \text { to } \mathrm{W}_{\mathrm{i}} \\ \mathrm{y}_{\mathrm{ij}} & \text { The distance from } \mathrm{W}_{\mathrm{i}} \text { to } \mathrm{C}_{\mathrm{j}} & \mathrm{q}_{\mathrm{ij}} & \text { The unit transportation cost from } \mathrm{W}_{\mathrm{i}} \text { to } \mathrm{C}_{\mathrm{j}} \\ \mathrm{r}_{\mathrm{u}} & \text { The unit management cost of } \mathrm{S}_{\mathrm{u}} & \mathrm{t}_{\mathrm{u}} & \text { The demand of } \mathrm{RS} \mathrm{S}_{\mathrm{u}} \\ \mathrm{g}_{\mathrm{i}} & \text { The management cost of } \mathrm{W}_{\mathrm{i}} & \mathrm{f}_{\mathrm{i}} & \text { The fixed rental cost of } \mathrm{W}_{\mathrm{i}} \\ \mathrm{a}_{\mathrm{i}} & \text { The maximum capacity of } \mathrm{W}_{\mathrm{i}} & \mathrm{e} & \text { The maximum number of } \mathrm{W}_{\mathrm{i}} \\ \mathrm{d}_{\mathrm{i}} & \text { The demand of } \mathrm{C}_{\mathrm{j}} & \mathrm{b}_{\mathrm{k}} & \text { The maximum supply capacity of } \mathrm{P}_{\mathrm{k}}\end{array}$




\section{Decision Variables:}

$\mathrm{W}_{\mathrm{ki}} \quad$ The flow of product from $\mathrm{P}_{\mathrm{k}}$ to $\mathrm{W}_{\mathrm{i}} \quad \mathrm{c}_{\mathrm{iu}} \quad$ The flow of product from $\mathrm{W}_{\mathrm{i}}$ to $\mathrm{S}_{\mathrm{u}}$

$\mathrm{h}_{\mathrm{ij}}$ The flow of product from $\mathrm{W}_{\mathrm{i}}$ to $\mathrm{C}_{\mathrm{j}}$

$\mathrm{Z}_{\mathrm{i}} \quad z_{i}=\left\{\begin{array}{l}1, \text { if distribution centre } \mathrm{w}_{\mathrm{i}} \text { is selected } \\ 0, \text { if otherwise }\end{array}\right.$

\section{Constrains:}

$$
\begin{aligned}
& \sum_{i=1}^{m} w_{k i} \leq b_{k} \\
& \sum_{k=1}^{L} w_{k i}=\sum_{j=1}^{n} h_{i j}+\sum_{u=1}^{n} c_{i u}, i=1,2, \cdots m \\
& \sum_{i=1}^{m} h_{i j}=d_{j}, j=1,2, \cdots, n \\
& \sum_{i=1}^{m} c_{i u}=t_{u}, u=1,2, \cdots, n \\
& \sum_{i=1}^{m} z_{i} \leq e \\
& \sum_{k=1}^{L} w_{k i} \leq a_{i} z_{i}
\end{aligned}
$$

Constrain (3) requires that the supply from factory to DC does not exceed its maximum supply; Constrain (4) states that the delivery volume of the DC from the factory should be equal to the quantity delivered to the consumer and the RS. That is to say, there is no inventory stored in each DC. Constrain (5) (6) shows that the demands pf customer and store should be satisfied; Constrain (7) specifies the maximum number of DCs; Constrain(8)specifies the maximum capacity of the DC.

There are two directions to solve DCL problem: approximate solution method and accurate solution method. The approximate solution can only be used as a basis for decision makers and can not be used as a final decision. Since the approximation method does not take into account the fixed costs and the unit storage costs of the alternative points when making a regional division, it is possible to select the DC at a higher fixed cost area, resulting in a high cost. Thus, decision makers often use accurate solution method.

The purpose of this paper is to solve the problem of distributed DCL, not only to achieve the goal of minimizing the cost, but also to maximize the level of consumer distribution services. This paper establishes a mixed integer programming model with binary variables, which is easier solved by Lingo software.

\section{Numerical Analysis}

Consider a small-scale distributed DCL problem. Assuming that the demand point of a clothing brand company $(\mathrm{C} 1, \mathrm{C} 2, \ldots, \mathrm{C} 15)$ is distributed in 15 cities in Jiangsu Province: Nanjing, Nantong, Taicang, Yixing, Changzhou, Changshu, Xuzhou, Yangzhou, Wuxi, Kunshan, Jiangyin, Yancheng, Suzhou, Lianyungang, Suqian and Zhenjiang; There are three factories (P1, P2, P3): Nantong, Changshu and Suzhou. The company plans to select up to four points as its own DC. And the demand for each CC and RS is known.

It is difficult to solve the multi-objective programming problem directly with lingo software, so it needs to do the appropriate conversion: First, Retain a more important objective function, obtained the corresponding objective function value; Second, The target function value is used as a constraint condition to solve another objective function value. There are two objective functions in this research: cost minimization and consumer delivery service level maximization. In this paper, the consumer delivery service level maximization is regarded as the first important goal. Therefore, objective 2 is satisfied first and objective 1 is satisfied later. 
The results are as follows: $Z(T R 6)=1, Z(T R 8)=1, Z(T R 15)=1, Z(T R 16)=1$. It indicates that Changshu, Yangzhou, Suqian and Zhenjiang should be selected as DCs, while the total cost is 564779RMB. Table 1 and Table 2 indicate the flow of product from factory to DC, also from DC to CC/RS.

Table 1 Flow from $\mathrm{P}_{\mathrm{k}}$ to $\mathrm{W}_{\mathrm{i}}$

\begin{tabular}{|c|c|c|c|c|}
\hline Factory & W6 & W8 & W15 & W16 \\
\hline P1 & 0 & 0 & 7742 & 2258 \\
\hline P2 & 8000 & 0 & 0 & 2000 \\
\hline P3 & 0 & 8000 & 0 & 3742 \\
\hline Total flow & 8000 & 8000 & 7742 & 8000 \\
\hline
\end{tabular}

Table 2 Flow from $\mathrm{W}_{\mathrm{i}}$ to $\mathrm{C}_{\mathrm{j}}\left(\mathrm{S}_{\mathrm{u}}\right)$

\begin{tabular}{|c|c|c|c|c|}
\hline Company & W6 & W8 & W15 & W16 \\
\hline C1(S1) & $0(3607)$ & $0(0)$ & $0(0)$ & $3607(0)$ \\
\hline C2(S2) & 721 & $0(0)$ & $0(0)$ & $0(721)$ \\
\hline$\ldots$ & $\ldots$ & $\ldots$ & $\ldots$ & $\ldots$ \\
\hline C16(S16) & $0(0)$ & $0(0)$ & $0(0)$ & $721(721)$ \\
\hline Total flow & 8000 & 8000 & 7742 & 8000 \\
\hline
\end{tabular}

\section{Conclusions}

In this paper we introduce a three-echelon supply chain based on dual marketing channel policy for the firm's strategic planning. The distinguish feature of our model is its consideration of consumer delivery service level. This model will have an important application in the regional or global supply chain network design with the consideration of consumer delivery service level.

This paper proposes a distributed DC solution based on the dual marketing channel policy. Considering the two factors of enterprise cost and consumer delivery service level, a multi-objective optimization model based on mixed integer programming is established. The quantity and location of DDCs are determined by model to improve the distribution efficiency of B2C commerce. Finally the validity of the model is verified by an example. The results show that establishment of a distributed DC is more cost-effective than building a single DC while the level of logistics services has been significantly improved.

Our future research direction is to consider more factors in the three-echelon supply chain based on dual marketing channel policy, such as product type, demand uncertainty, and so on. So that it can be enhance its applicability to real-life scenarios. On the other hand, wen can also extend our research through designing new solution methods to solve this multi-objective mixed integer programming model.

\section{References}

[1] King Ruth-C. Xia Ravi-Sen-\&-Mu. Impact of Web based e Commerce on Channel Strategy in Retailing [J]. International Journal of Electronic Commerce, 2014, 8(3): 103-130.

[2] Lu Qihui, Liu Nan. Effects of e-commerce channel entry in a two-echelon supply chain: A conparative analysis of single and dual channel [J]. Japanese Journal of Production Economics, 2015, 165: 100-111. 
[3] Li Lin, Liu Shixin, Tang Jiafu. Basic Models for Solving Distribution Center Location Problems: A Review [J]. International Conference on Service Systems and Service Management, 2007, 7(7): 1-5.

[4] Melo M. T. Nickel S. Saldanha-da-gama F. Facility location and supply chain management: A review [J]. European Journal of Operational Research, 2009, 196(2): 401-412.

[5] Shankar BL, Basavarajappa S, Chen JCH. Location and Allocation Decisions for Multi-echelon Supply Chain Network: a Multi-objective Evolutionary Approach [J]. Expert Systems with Applications, 2013, 40(2): 551-562.

[6] Berger Rosemary-T. Coullard Collette-R. Daskin Mark-S. Location-Routing Problems with Distance Constraints [J]. Transportation Science, 2007, 41(1): 29-43.

[7] Galvao Roberto-D. Acosta Espejo-Luis-Gonzalo, Boffey Brian. Load balancing and capacity constraints in a hierarchical location model [J]. European Journal of Operational Research, 2006, 172(2): 631-646. 